Applied Mathematical Sciences, Vol. 9, 2015, no. 12, 551 - 556

HIKARI Ltd, www.m-hikari.com

http://dx.doi.org/10.12988/ams.2015.411897

\title{
Graceful Labeling of Roman Rings Having Cycle with 6 Vertices
}

\author{
G. Sathiamoorthy \\ School of Humanities and Sciences, SASTRA University, India \\ T. N. Janakiraman \\ Department of Mathematics, NIT Trichy, India \\ Copyright (C) 2014 G. Sathiamoorthy and T. N. Janakiraman. This is an open access \\ article distributed under the Creative Commons Attribution License, which permits unre- \\ stricted use, distribution, and reproduction in any medium, provided the original work is
} properly cited.

\begin{abstract}
Roman rings can be obtained by introducing $\mathrm{n}$ copies of cycle $\mathrm{C}_{6}$ with 6 vertices, which are merged respectively to $\mathrm{n}$ teeth of comb graph $\mathrm{P}_{n} \odot \mathrm{L}_{1}$. In this paper, it is proved Roman rings with cycle $\mathrm{C}_{6}$ are graceful.
\end{abstract}

Mathematics Subject Classification: 05C78

Keywords: Graceful labeling, Roman rings, cycle graph

\section{Introduction}

Graphs considered in this paper are simple finite and undirected. In general $\mathrm{G}(\mathrm{V}, \mathrm{E})$ denotes the graph $\mathrm{G}$ with vertex set $\mathrm{V}(\mathrm{G})$, edge set $\mathrm{E}(\mathrm{G})$, such that $|V(G)|=$ p vertices $|E(G)|=$ q edges. A labeling of the vertices of $\mathrm{G}$ with the numbers from 0 to $\mathrm{q}$ is an injective map $\phi: V \rightarrow\{0,1, \ldots q\}$. A graph $\mathrm{G}$ is graceful if there exists a labeling of its vertices such that the map $\phi^{*}$ : $\mathrm{E}$ $\rightarrow\{1,2, \ldots q\}$ given by $\phi^{*}(\mathrm{uv})=|\phi(u)-\phi(v)|$, where $\mathrm{u}, \mathrm{v} \in \mathrm{V}$ and $\mathrm{uv} \in \mathrm{E}$ is a bijection.

A graph that admits graceful labeling is called graceful graph. The notation 
graceful labeling was introduced Rosa[3] with the name valuation.

Gallian[2] gives the extensive survey of contributions to graceful labeling of variety of graphs. Rosa[3], [4] showed that the cycle $\mathrm{C}_{n}$ is graceful if and only if $\mathrm{n}=0$ or $3(\bmod 4)$. Bhat-Nayak and Selvam [1] have shown that the n-cone (also called the n-point suspension of $\mathrm{C}_{m}$ ) $\mathrm{C}_{m}+\overline{K_{n}}$ is graceful when $\mathrm{m}=0$ or $3(\bmod 12)$. They also proved the gracefulness of $\mathrm{C}_{4}+\overline{K_{n}}, \mathrm{C}_{5}+\overline{K_{2}}, \mathrm{C}_{7}$ $+\overline{K_{n}}, \mathrm{C}_{9}+\overline{K_{2}}, \mathrm{C}_{11}+\overline{K_{n}}$ and $\mathrm{C}_{19}+\overline{K_{n}}$. Seo [5] proved Gracefulness of the union of cycles and paths.

\section{Main Result}

Let $\mathrm{R}_{1}, \mathrm{R}_{2}, \ldots, \mathrm{R}_{n}$ be $\mathrm{n}$ copies of cycle $\mathrm{C}_{6}$ (we term here as rings). Let the supporting points on the $n$ rings $\mathrm{R}_{1}, \mathrm{R}_{2}, \ldots, \mathrm{R}_{n}$ be $\mathrm{t}_{1}, \mathrm{t}_{2}, \ldots, \mathrm{t}_{n}$, which are merged respectively to $\mathrm{n}$ teeth of comb graph $\mathrm{P}_{n} \odot \mathrm{L}_{1}$. Let $\mathrm{b}_{1}, \mathrm{~b}_{2}, \mathrm{~b}_{3}, \ldots$, $\mathrm{b}_{n}$ be base points of the comb graph from which $\mathrm{n}$ rings of equal length say $\mathrm{m}$, are hanging, each of which at a tooth of $\mathrm{n}$ teeth respectively. The resulting structure is called Roman rings $\mathrm{R}(6, \mathrm{n})$. Let the points of $\mathrm{i}^{\text {th }}$ ring be $\mathrm{c}_{1}^{i}, \mathrm{c}_{2}^{i}$, $\ldots, \mathrm{c}_{m-1}^{i}$ for $\mathrm{i}=1,2, \ldots, \mathrm{n}$.

From the above definition of $\mathrm{R}(6, \mathrm{n})$ graph, $|V(R(6, n))|=7 \mathrm{n}$. Also, the number of edges of $\mathrm{R}(6, \mathrm{n})$ is $|E(R(6, n))|=8 \mathrm{n}-1$.

Theorem 2.1. The Roman rings $R(6, n)$ is graceful.

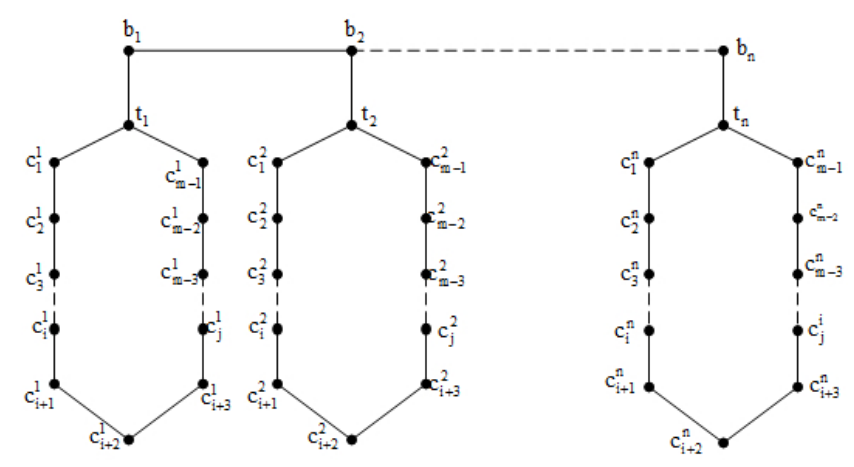

Figure 1: General form of $\mathrm{R}(6, \mathrm{n})$

The labeling of $(\mathrm{n}-1)$ rings are as follows:-

Step $1: \phi\left(b_{1}\right)=0, \phi\left(t_{1}\right)=q . \quad \phi\left(c_{1}^{1}\right)=1, \phi\left(c_{2}^{1}\right)=2$.

Step $2: \phi\left(b_{2}\right)=q-3, \phi\left(t_{2}\right)=3 . \quad \phi\left(c_{1}^{2}\right)=q-1, \phi\left(c_{2}^{2}\right)=q-2$.

(Let $\mathrm{n}=2 \lambda+1$ for odd and $\mathrm{n}=2 \lambda$ for even)

Case 1: $\mathbf{n}$ is odd, then 
Step $3: \phi\left(b_{2 i+1}\right)=\phi\left(b_{2 i-1}\right)+4,1 \leq \mathrm{i} \leq \lambda-1$.

Step $4: \phi\left(\mathrm{t}_{2 i+1}\right)=\mathrm{q}-\phi\left(\mathrm{b}_{2 i+1}\right), 1 \leq \mathrm{i} \leq \lambda-1$.

Step $5: \phi\left(\mathrm{b}_{2 i+2}\right)=\phi\left(\mathrm{b}_{2 i}\right)-4,1 \leq \mathrm{i} \leq \lambda-1$.

Step $6: \phi\left(\mathrm{t}_{2 i+2}\right)=\phi\left(\mathrm{t}_{2 i}\right)+4,1 \leq \mathrm{i} \leq \lambda-1$.

Case 2: $\mathrm{n}$ is even, then

Step $3: \phi\left(b_{2 i+1}\right)=\phi\left(b_{2 i-1}\right)+4,1 \leq \mathrm{i} \leq \lambda-1$.

Step $4: \phi\left(\mathrm{t}_{2 i+1}\right)=\mathrm{q}-\phi\left(\mathrm{b}_{2 i+1}\right), 1 \leq \mathrm{i} \leq \lambda-1$.

Step $5: \phi\left(\mathrm{b}_{2 i+2}\right)=\phi\left(\mathrm{b}_{2 i}\right)-4,1 \leq \mathrm{i} \leq \lambda-1$.

Step $6: \phi\left(\mathrm{t}_{2 i+2}\right)=\phi\left(\mathrm{t}_{2 i}\right)+4,1 \leq \mathrm{i} \leq \lambda-1$.

Step $7: \phi\left(c_{3}^{1}\right)=(n-2) 2+12, \phi\left(c_{4}^{1}\right)=\phi\left(c_{3}^{1}\right)+2$.

Step $8: \phi\left(c_{3}^{2}\right)=(n-3) 6+7, \phi\left(c_{4}^{2}\right)=\phi\left(c_{3}^{2}\right)+2$.

Case 1: $\mathbf{n}$ is odd (continue), then

Step $9: \phi\left(\mathrm{c}_{3}^{2 i+1}\right)=\phi\left(\mathrm{c}_{3}^{2 i-1}\right)+8,1 \leq \mathrm{i} \leq \lambda-1$.

Step $10: \phi\left(\mathrm{c}_{4}^{2 i+1}\right)=\phi\left(\mathrm{c}_{4}^{2 i-1}\right)+8,1 \leq \mathrm{i} \leq \lambda-1$.

Step $11: \phi\left(c_{3}^{2 i+2}\right)=\phi\left(c_{3}^{2 i}\right)-8,1 \leq \mathrm{i} \leq \lambda-1$.

Step $12: \phi\left(c_{4}^{2 i+2}\right)=\phi\left(c_{4}^{2 i}\right)-8,1 \leq \mathrm{i} \leq \lambda-1$.

Case 2: $\mathbf{n}$ is even(continue), then

Step $9: \phi\left(c_{3}^{2 i+1}\right)=\phi\left(c_{3}^{2 i-1}\right)+8,1 \leq \mathrm{i} \leq \lambda-1$.

Step $10: \phi\left(\mathrm{c}_{4}^{2 i+1}\right)=\phi\left(\mathrm{c}_{4}^{2 i-1}\right)+8,1 \leq \mathrm{i} \leq \lambda-1$.

Step $11: \phi\left(c_{3}^{2 i+2}\right)=\phi\left(c_{3}^{2 i}\right)-8,1 \leq \mathrm{i} \leq \lambda-1$.

Step $12: \phi\left(c_{4}^{2 i+2}\right)=\phi\left(c_{4}^{2 i}\right)-8,1 \leq \mathrm{i} \leq \lambda-1$.

The remaining $(\mathrm{n}-1) 2+7$ edges starting from 1 to $2(\mathrm{n}-3)+12$. Let $\mathrm{e}_{i}=$ $2(\mathrm{n}-3)+12$. The remaining edges formed in $\mathrm{n}$ pair relations starting from $\left(\mathrm{e}_{i}, \mathrm{e}_{i}-2\right),\left(\mathrm{e}_{i}-1, \mathrm{e}_{i}-3\right),\left(\mathrm{e}_{i}-4, \mathrm{e}_{i}-6\right),\left(\mathrm{e}_{i}-5, \mathrm{e}_{i}-7\right), \ldots$ The labeling of $\phi\left(c_{5}\right)$ are as follows :-

Step 13 : select maximum edge value pair among $\left(\phi\left(c_{3}^{i}\right), \phi\left(c_{4}^{i}\right)\right), \mathrm{i}=1$ to $\mathrm{n}$ $-1$.

Step 14 : substitute maximum edge value pair and the resultant vertex lies in $3(n-2)+1$ to $q-2(n-1)$. 
Step 15 : if not continue with other decreasing order of vertex pairs.

Step 16 : select 2 nd edge pair and continue the above steps.

The remaining 7 edges consists of $(n-1)^{t h}$ pair in the above $n$ pairs and remaining edges from 1 to 7 .

Last ring consists of 6 edges.

Now, induced edge labeling are as follows :-

$1: \phi^{*}\left(b_{1} t_{1}\right)=$ q. $2: \phi^{*}\left(t_{1} c_{1}^{1}\right)=\mathrm{q}-1 . \quad 3: \phi^{*}\left(t_{1} c_{2}^{1}\right)=\mathrm{q}-2$.

$4: \phi^{*}\left(b_{1} b_{2}\right)=\mathrm{q}-3.5: \phi^{*}\left(t_{2} c_{1}^{2}\right)=\mathrm{q}-4 . \quad 6: \phi^{*}\left(t_{2} c_{2}^{2}\right)=\mathrm{q}-5$.

$7: \phi^{*}\left(b_{2} t_{2}\right)=\mathrm{q}-6 . \quad 8: \phi^{*}\left(b_{2} b_{3}\right)=\mathrm{q}-7$.

Case 1: $\mathbf{n}$ is odd, then

Induced edge labeling of odd segment are as follows :-

$9: \phi^{*}\left(b_{2 d+1} t_{2 d+1}\right)=\mathrm{q}-8 \mathrm{~d}, 1 \leq \mathrm{d} \leq \lambda-1$.

$10: \phi^{*}\left(t_{2 d+1} c_{1}^{2 d+1}\right)=\mathrm{q}-1-8 \mathrm{~d}, 1 \leq \mathrm{d} \leq \lambda-1$.

$11: \phi^{*}\left(t_{2 d+1} c_{2}^{2 d+1}\right)=\mathrm{q}-2-8 \mathrm{~d}, 1 \leq \mathrm{d} \leq \lambda-1$.

$12: \phi^{*}\left(b_{2 d+1} b_{2 d+2}\right)=\mathrm{q}-3-8 \mathrm{~d}, 1 \leq \mathrm{d} \leq \lambda-1$.

Induced edge labeling of even segment are as follows :-

$13: \phi^{*}\left(t_{2 d+2} c_{1}^{2 d+2}\right)=\mathrm{q}-4-8 \mathrm{~d}, 1 \leq \mathrm{d} \leq \lambda-1$.

$14: \phi^{*}\left(t_{2 d+2} c_{2}^{2 d+2}\right)=\mathrm{q}-5-8 \mathrm{~d}, 1 \leq \mathrm{d} \leq \lambda-1$.

$15: \phi^{*}\left(b_{2 d+1} t_{2 d+2}\right)=\mathrm{q}-6-8 \mathrm{~d}, 1 \leq \mathrm{d} \leq \lambda-1$.

$16: \phi^{*}\left(b_{2 d+2} b_{2 d+3}\right)=\mathrm{q}-7-8 \mathrm{~d}, 1 \leq \mathrm{d} \leq \lambda-1$.

Case 2: $\mathbf{n}$ is even, then

Induced edge labeling of odd segment are as follows :-

$9: \phi^{*}\left(b_{2 d+1} t_{2 d+1}\right)=\mathrm{q}-8 \mathrm{~d}, 1 \leq \mathrm{d} \leq \lambda-1$.

$10: \phi^{*}\left(t_{2 d+1} c_{1}^{2 d+1}\right)=\mathrm{q}-1-8 \mathrm{~d}, 1 \leq \mathrm{d} \leq \lambda-1$.

$11: \phi^{*}\left(t_{2 d+1} c_{2}^{2 d+1}\right)=\mathrm{q}-2-8 \mathrm{~d}, 1 \leq \mathrm{d} \leq \lambda-1$.

$12: \phi^{*}\left(b_{2 d+1} b_{2 d+2}\right)=\mathrm{q}-3-8 \mathrm{~d}, 1 \leq \mathrm{d} \leq \lambda-2$.

Induced edge labeling of even segment are as follows :-

$13: \phi^{*}\left(t_{2 d+2} c_{1}^{2 d+2}\right)=\mathrm{q}-4-8 \mathrm{~d}, 1 \leq \mathrm{d} \leq \lambda-2$.

$14: \phi^{*}\left(t_{2 d+2} c_{2}^{2 d+2}\right)=\mathrm{q}-5-8 \mathrm{~d}, 1 \leq \mathrm{d} \leq \lambda-2$. 
$15: \phi^{*}\left(b_{2 d+1} t_{2 d+2}\right)=\mathrm{q}-6-8 \mathrm{~d}, 1 \leq \mathrm{d} \leq \lambda-2$.

$16: \phi^{*}\left(b_{2 d+2} b_{2 d+3}\right)=\mathrm{q}-7-8 \mathrm{~d}, 1 \leq \mathrm{d} \leq \lambda-2$.

Step a : select maximum edge value from the available assigned values of pair adjacent vertices $\left(\left(c_{3}^{i}\right),\left(c_{4}^{i}\right)\right), \mathrm{i}=1$ to $\mathrm{n}-1$.

Step b : substitute maximum edge value pair and the resultant vertex value lies in the vertex set from $3(n-2)+1$ to $q-2(n-1)$.

Step c : if not continue with other decreasing order of vertex pairs.

Step d : select 2nd edge pair and continue the above steps.

The remaining 7 edges consists of $(n-1)^{t h}$ pair in the above $n$ pairs and remaining edges from 1 to 7 substituted in the last ring.

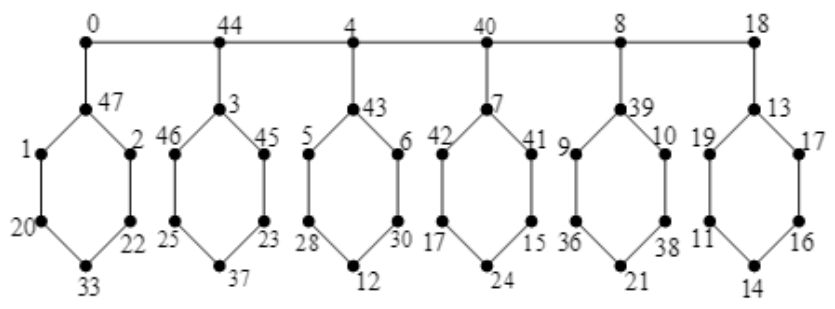

Figure 2: Example for $\mathrm{R}(6,6)$

\section{Conclusion}

Using the above procedure, it is proved that Roman rings $R(6, n)$ is graceful.

\section{References}

[1] V. N. Bhat-Nayak and A. Selvam, Gracefulness of n-cone Cm V Kc n, Ars Combin, 66 2003, 283-298.

[2] Gallian, J A, A Dynamic Survey of Graceful Labeling, The Electronic Journal of Combinatorics, fifteenth edition, December 2012.

[3] A. Rosa, On certain valuations of the vertices of a graph, Theory of Graphs (Internat. Symposium, Rome, July 1966), 1967, Gordon and Breach, N. Y. and Dunod Paris, 349-355. 
[4] A. Rosa, On cyclic decompositions of the complete graphs, Doctoral Thesis, Bratislava, 1965 (in Slovak).

[5] M. A. Seoud, A. E. I. Abdel Maqsoud, and J. Sheehan, Gracefulness of the union of cycles and paths, Ars Combin., 54 (2000) 283-292.

Received: November 16, 2014, Publsihed: January 7, 2015 